\title{
Livecasting without the live: The multiple temporalities of National Theatre at Home
}

\author{
Sarah Byrne \\ University of Reading
}

\begin{abstract}
Since the 2009 launch of NT Live, the National Theatre has been at the forefront of UK livecasting so the calls to respond to the complete lockdown of the UK in March 2020 weren't surprising. This paper will analyse how this pandemic response utilised the multiple temporalities of NT Live to create a theatrical event in viewers' homes. Despite using past recordings, the NT At Home programme was a response to a specific historical event and was structured around an "ontological now" that in return shaped the reception of those recordings. NT Live capitalised on the liveness and the exclusivity of their broadcasts. Performances were shown at a set time, streamed simultaneously into cinemas. NT At Home challenged every part of this system of liveness and in doing so created its own contradictory and fluid temporal identity. In this paper I will draw on liveness studies from multiple disciplines to cover three aspects of these new temporalities and present a case study of liveness practice.
\end{abstract}

Sin dal lancio nel 2009 di NT Live, il National Theatre è stato protagonista nel livecasting nel Regno Unito; non sorprende quindi l'aspettativa di una risposta dell'istituzione teatrale a seguito del lockdown di marzo 2020. Il presente articolo cerca di analizzare questa risposta pandemica da parte dell'NT Live abbia utilizzato molteplici temporalità per ricreare un senso dell'evento teatrale nelle case degli spettatori. Nonostante l'utilizzo di materiale d'archivio, l'iniziativa NT At Home ha costituito una risposta a uno specifico evento storico strutturata attorno un "ora ontologico" che modellato la ricezione di questo materiale: NT Live capitalizzava sulla liveness e sull'esclusività della trasmissione, con performance mostrate a un orario specifico e trasmesse simultaneamente al cinema; NT At Home rielabora invece questo sistema di liveness, creando il proprio sento di una temporalità fluida e contraddittoria. L'articolo attinge quindi ad approcci sulla liveness provenienti da molteplici discipline per esaminare tre aspetti in particolare di questa nuova temporalità e un caso di studio specifico di "pratica di liveness".

\section{Key Words}

National Theatre, Livecasting, Event Cinema, Streaming 


\section{Introduction}

The UK went into a complete lockdown on $23^{\text {rd }}$ March 2020 in response to the COVID-19 pandemic. One of the immediate reactions to that closure was a call for arts institutions to somehow make some of their recordings of live performance available for the public. For over a decade before that lockdown, the UK livecasting industry had seen rapid development, the simultaneous broadcast of live performances into cinemas grew in both scope and popularity. Accordingly, as livecasting has become increasingly prevalent within our cultural landscape, and as the impact is felt of digital distribution and new modes of engagement with live theatre, so our understanding and definitions of liveness and live experience are bound to expand.

Modern mainstream livecasting began in the UK in the early 2000s with opera and concert films, and brought together, in a new way, disparate audiences from across the world to watch productions they would not usually have had straightforward access to. In June 2009, London's National Theatre first attempted the same for theatrical performance when it broadcast its production of Phèdre, starring Helen Mirren, as the opener in a pilot season of its National Theatre Live (NT Live) programme. While it is important to acknowledge that other institutions developed their own programmes of livecasts ${ }^{1}$, because of its role at the forefront of mainstream UK livecasting and its dominance in the medium, the National occupied a significant cultural and industrial position. Consequently, it is unsurprising that, in 2020, requests were made for its recorded content to be made available for people who could no longer attend cinemas and theatres. In April that year, the start of the National Theatre at Home programme was announced, where past livecasts from NT Live would be shared with audiences across the world via YouTube.

Perhaps paradoxically, the term livecasting is often used to encompass the practice of screening recordings of theatre performances in front of live audiences. However, as outlined below, for most of its broadcasts, NT Live streams simultaneously, as do other UK-

\footnotetext{
${ }^{1}$ For a broader overview of mainstream UK livecasting I would recommend the Live-to-Digital report compiled by Karpf Reidy et al. and Abrahams and Tuck's Understand the Impact of Event Cinema report for the BFI and ACE. Bahkshi and Throsby's work addressed widespread early concerns about the potential threat posed to live theatre by livecasting and the work of Atkinson and Kennedy on live cinema and event cinema is useful for situating livecasting in the broader UK cultural landscape.
} 
based mainstream livecasting theatres, such as Shakespeare's Globe and the Royal Shakespeare Company. Furthermore, in the UK, livecasts are classed by cinemas as "Event Cinema" while in the US, they are often referred to as "Alternative Content". The Event Cinema Association describes "Event Cinema" as «increasingly defined by its methodology of release rather than by the content. Typically, this is a 'one or two nights only' release strategy, often accompanied by encore screenings ${ }^{2}$. Indeed, this sense of event is a core convention of the NT Live broadcasts, featuring heavily in their marketing materials. Though the emphasis in the ECA's statement is on distribution rather than content it has, as I shall explain further, a direct impact on the look and feel of their livecasts.

I acknowledge that other British cultural institutions of varying sizes and scope made content available during the pandemic but I have chosen to focus on National Theatre at Home as the National's pandemic response for two reasons: firstly, because of its prominence in this medium; and secondly, because the dynamics and aesthetics of liveness and live performance were already complex in the National's livecasting model. Indeed, this complexity was only heightened as the pandemic began to hit. Of vital importance for my argument here is Stephanie Marriott's observation that space and time are both highly contextualised $^{3}$, particularly since National Theatre at Home navigates a transition from the live event of NT Live, into something with a "similar" phenomenological register to liveness, but one that is, nonetheless, "distinct". That distinctness is a result of fundamental contextual differences in how these two modes of watching recorded theatre have engaged audiences. For NT Live, for example, liveness was both a key selling point and an integral part of the hybrid medium's identity, whereas for National Theatre at Home, liveness manifested both as and through spectatorial choice for the individual spectator.

Furthermore, since the broadcast of Phèdre, there have been over eighty original NT Live broadcasts in yearly seasons, and audiences for these have expanded to include cinema goers all over the world. Each broadcast so far has been shown at a set time, streamed live into cinemas. It has subsequently been repeated for a global audience and then finally, in an encore performance, for UK audiences, the latter depending on its

\footnotetext{
${ }^{2}$ https://eventcinemaassociation.org/about-us/ (accessed 24 November 2021).

${ }^{3}$ S. Marriott, Live television: Time, space and the live broadcast event, Sage, Los Angeles 2007.
} 
popularity. Following this, the only place the broadcast can be viewed is in the NT Archive in London. The spectator's temporal and spatial access to the NT Live recording was conducted by the National Theatre from its first "going live" moment through its repeat and admission to the archive. It is this temporality that means that the broadcast, in each of its iterations, retains a sense of event. Spectators have exclusive access because they are present at a specific date and time and it is challenging to see the broadcast outside of those parameters, echoing the ephemerality of other live theatre events.

Overall this is typical of livecasting's methodology of release as detailed by the Event Cinema Association. Fundamentally, livecasting is not just about the recreation of live performance but the recreation of a live event. Event here means an occurrence of significance at a set point in time, an admittedly broad definition. The emphasis is on the experience rather than the content. Dayan and Katz describe media events as inviting the viewer to halt their routine in order to participate in something «special» and that liveness is a significant part of the experiential identity of the event ${ }^{4}$ As this paper will demonstrate, the replication of a live event like this is a complicated and nuanced process. This is in part due to the complex and sometimes contradictory institutional aims of broadcasters like the National Theatre. For example, before the broadcast of Phèdre, the cinema audience was shown a live interview with the then creative director of the $\mathrm{Na}$ tional Theatre and director of the play, Nicholas Hytner. He said:

\begin{abstract}
This is not a movie that we're making. What we're trying to do here, and we don't know yet whether we'll succeed, is convey something of the excitement, a lot we hope, of the excitement of live theatre to cinemas across the world... we're trying to give cinema audiences what we think the audience in the theatre would be most likely to be focusing on at any one moment and the great thing is it's live... we can reproduce the liveness and we hope we can give you something a little bit extra... we can make it maybe both grand and intimate. ${ }^{5}$
\end{abstract}

On the surface, «both grand and intimate» seems contradictory, both in terms of the audience's experience of the event and the aesthetics of the recorded performance, but it is indicative of the constant negotiation of multiple spatio-temporal dynamics that

${ }^{4}$ D. Dayan, E. Katz. Media Events: The Live Broadcasting of History, Harvard University Press Cambridge and London 1992, p. 5.

${ }^{5} \mathrm{~N}$. Hytner, Phèdre Pre-show Interview, 25 June 2009. 
is part of NT Live and of livecasting as a hybrid medium. In turn, National Theatre at Home challenged every single part of NT Live's system of liveness and engagement and in doing so it created its own unique temporal multiplicity, one that is both complex and fluid. This was partly through necessity. NT Live was tied closely to theatre and cinema exhibition spaces, both of which were inaccessible in the pandemic. The archive too was closed during lockdown, meaning that research and engagement with older texts was unable to take place. By moving to a digital space and means of distribution, National Theatre at Home had to create a new identity and restructure its modes of engagement.

The schedule for National Theatre at Home was the same throughout the sixteen weeks the programme was active. The broadcast would premiere on the National's YouTube channel ${ }^{6}$ on a Thursday night at $7 \mathrm{pm}$. After that, the broadcast was available on YouTube for one week until the premiere of the next broadcast on the following Thursday at $7 \mathrm{pm}$. Within that time frame the broadcast was available whenever the spectator wished and could be watched multiple times. The exception to this schedule was the broadcast of Frankenstein, directed by Danny Boyle? ${ }^{7}$. This production had two NT Live broadcasts in 2011 as the role of Frankenstein and the Creature was shared by two actors. NT Live broadcast the production twice with each actor playing both roles alternately. Both broadcasts were re-released as part of National Theatre at Home, the first on 30 April and the second on 1 May meaning that both sets of performances got a premiere broadcast and then were available for a week following. Each version was treated as a separate performance event and that specific sense of event was curated around it through scheduling and its temporal identity.

In order to analyse changing modes of engagement with live experiences and the impact of digital distribution methods as a pandemic response this paper will draw on liveness scholarship and close analysis to cover three aspects of this new temporality created by National Theatre at Home that defines its identity as a hybrid medium. The first section, NT Live and Liveness, explores the programme's relationship with and expansion of NT Live's notion of liveness. Section two is The Live Event and analyses the in-

\footnotetext{
${ }^{6}$ https://www.youtube.com/c/NationalTheatre (accessed 24 November 2021).

${ }^{7}$ https://www.nationaltheatre.org.uk/shows/nt-at-home-frankenstein (accessed 24 November 2021).
} 
clusivity and accessibility of National Theatre at Home as an event despite the fact that the performance is a recording and situated in the past. In the final section, Pandemic Response, I will explore how National Theatre at Home was a specific reaction to the "now" of the pandemic and subsequent lockdown, situating the programme in a specific historical moment.

\section{NT Live and Liveness}

To accurately approach the scale of the change from live broadcast to streamed event it must be acknowledged that the concept of liveness is a complex one. It is also one that exists beyond performance studies alone. Because of the medium hybridity of livecasting, the entirety of the thesis project from which this paper derives has drawn not only on theatre scholarship but also new media and television studies. Livecasting in the UK in particular is very televisual in its modes of delivery, resembling both arts television and early television drama where much of the content was simultaneous broadcasts of plays or extracts of plays from West End theatres ${ }^{8}$. Stephanie Marriott's scholarship on live television, with its emphasis on the highly contextual nature of time and space, is one such example, offering a useful framework through which to examine the spatiotemporal identity of NT Live and National Theatre at Home.

Marriott uses deictic expressions to illustrate her ideas. These are words and phrases where the meaning is dependent on context. So the definition of "then" and "now" is contingent on the specific situation in which those terms are being used. Understanding this context allows us to understand the definition. Considering National Theatre at Home broadcasts in light of Marriott's approach, a particular set of complexities become evident, since National Theatre at Home broadcasts made extensive use of the aesthetics of liveness while being very much an artefact of a previous time. There was a contradiction between what the audience saw, live audience interaction with performers, and how they were seeing it, after the fact in a home setting. This became exacerbated as the onscreen pre-COVID world, without social distancing or quarantine, became increasingly removed from our then current situation.

\footnotetext{
8J. Jacobs, The Intimate Screen: Early British TV Drama, Oxford University Press, Oxford 2000, pp. 33-37.
} 
The performances looked live even though they weren't because liveness was built into the structure and aesthetics of the NT Live broadcasts that were repurposed for National Theatre at Home. These aesthetics of liveness included the presence of an audience in the theatre auditorium. The majority of NT Live broadcasts featured shots of the theatre audience at the start and end, many also cut to wide shots of the audience during the performance. The sounds of applause, laughter or other reactions were also present. These aesthetic conventions of liveness work together in an NT Live broadcast to remind the cinema audience that they are temporally co-present and to draw a connection between the experience of those spectators in the auditorium and those in the various cinema spaces up and down the country.

The hashtag \#NationalTheatreAtHome was used on social media and viewers were encouraged to engage with it across all platforms, creating "spaces" for audiences to discuss the productions and share their experiences. Social media had been used similarly for NT Live, with people being encouraged to tweet about their experiences from cinemas. With National Theatre at Home there was a greater necessity for this space creation because of audiences being separated both spatially, and depending on when they chose to engage with the broadcast, temporally. Much of the NT Live branding was retained in the broadcast to establish the origins of the footage. As mentioned in the introduction, due to the scale and scope of the NT Live programme, livecasting in the UK is very closely linked with the National Theatre as both an institution and a brand. National Theatre at Home became an extension of that identity.

The paratextual material was also reconfigured to align with the new method of broadcasting. Paratexts are contextualising material that provide context to the main text while also helping to define the "here" and "now" in the case of livecasts. In the case of theatre livecasts, this can include interviews with the cast and crew, footage of the rehearsal rooms, and short films on the historical or social themes of the play. In NT Live broadcasts, and those from other institutions, paratextual material often forms part of the interval or pre-show content. In the National Theatre at Home broadcasts, the plays started straight away and the intervals were replaced by short pauses of around two minutes. These were often blank, black screens with either a countdown to the second 
act or a message about the importance of the arts as a balm during the pandemic. Later in the pandemic these pauses also featured still ads for the National Theatre. There was no longer any time or space in those broadcasts for the paratexts but they were not removed from the experience entirely. Instead, the means of engaging with them became another spectatorial choice for the viewers.

Film and TV scholar Jonathan Gray categorises paratexts by when the consumer encounters them. Entryway paratexts, as the name suggests, precede the main text and influence the viewers' method of engagement with them. In medias res paratexts come after (or sometimes during) the encounter with the text ${ }^{9}$. Gray does not write about livecasts specifically but they do make use of paratexts. Examples of the paratexts featured in an NT Live livecast are short films about the cultural or historical context of the plays and interviews with the cast and crew of a production. If the recorded performance is considered to be the main text, the livecast paratexts played before the performance fall definitively into the first category, literally guiding the viewers entrance to the text and guiding them on how they should engage with it. The interval content, for those broadcasts that have one, is in medias res in the sense that it is accessed in the middle of the text but it also performs the function of guiding the viewer into the second act. Functionally they are the same, providing context for the viewer not just in terms of the performance, but the experience as a whole.

For National Theatre at Home the paratextual material was compiled into playlists on You Tube and the National's website, available both in the lead up to the play being posted online and then left up once the play had been removed and the next premiere had taken place. The paratexts online were a combination of those created for the original cinema broadcast and new material created during lockdown. You can see some of the playlists, grouped by production, still available to view at the time of writing this paper $^{10}$. In a sense, the paratexts could be classified depending on how the viewer chooses to engage. The difference is intention. NT Live paratexts were created to be viewed either before the performance or during the interval. There was no element of choice on

\footnotetext{
9. Gray, Show Sold Separately: Promos, Spoilers and Other Media Paratexts, New York University Press, New York 2010, p. 23.

${ }^{10}$ https://www.youtube.com/c/NationalTheatre/playlists
} 
the part of the viewer in when they could engage with the paratext, beyond the choice to leave the cinema auditorium. In National Theatre at Home "then" and "now" became less tangible concepts, dependent on audience behaviour and choices.

The removal of paratexts from the main text of a livecast repurposes them. Marriott writes about commentaries, a form of paratext, that are positioned over pre-recorded footage in otherwise "live" television: «The commentary on events that occurred earlier...offers an overview of the event which is largely stripped of both subjective and intersubjective elements and which imposes a chronological order on the material on display ${ }^{11}$.

Though not commentaries, the paratexts positioned around the National Theatre at Home broadcasts offer a similar overview of the event. The length of the experience depends on the choices of the spectator, as does the depth of the engagement. It is less of an event in that there is no fixed date and time and so no fixed temporality or temporal identity. The broadcast is firmly set in the past, despite the text being constructed with the visual conventions of liveness. The same is true of the encore broadcast that followed NT Live broadcasts by a few months when they proved popular. A tension exists between the look of the broadcast and its reality in both cases. In addition, with National Theatre at Home there were elements of immediacy in response to events that were happening concurrently, further complicating the nature of the liveness of the broadcast. The paper will address this later on.

The first four weeks of performances was reminiscent of the pilot season of NT Live. In the aforementioned interview screened before the NT Live broadcast of Phèdre, Nicholas Hytner described the pilot season of NT Live as «very much a sampler of the National's work: classical work, theatrically adventurous work like Nation and new plays like The Habit of $A r t{ }^{12}$. It stands to reason then, if one of the aims of National Theatre at Home was to retain the National's position at the forefront of UK mainstream livecasting, that they would seek to provide another such sampler of the scope of their work to National Theatre at Home audiences.

\footnotetext{
${ }^{11}$ S. Marriott, op. cit., p. 65.

${ }^{12}$ N. Hytner, Phèdre pre-show interview with Jeremy Irons, NT Live, 25th June 2009.
} 
Both programmes are comprised of a diverse range of content, not only in terms of genre and format but also tone. It was a statement of intention and a demonstration of the scope and scale of the NT Live project. National Theatre at Home made a similar statement. Though the two programmes are from the same institution, National Theatre at Home would have garnered new viewers that needed that scope and scale mapped out for them. It connected two related programmes and guided the expectations of the spectator. Arguably, National Theatre at Home started with the piece of new writing because One Man, Two Guvnors was the most upbeat of the first four broadcasts and had the broadest appeal for audiences in an anxious and uncertain times. However, it is also the one that employs the greatest amount of interaction with the audience and the broadcast that looks the most like a live event.

Multiple visual hallmarks of liveness were retained in a theatre recording despite the context completely changing. Livecasts made extensive use of footage of the theatre audience to re-enforce the co-presence with the cinema audience. Co-presence has always been a key convention of the theatre going experience that is difficult to replicate in a livecast, even more so in National Theatre at Home than NT Live. In an NT Live broadcast a spectator was part of an audience in the cinema space, a configuration that shared some similarities with the theatre spaces from which NT Live performances were broadcast. This similarity heightened the experience, especially when paired with the images of the theatre viewers seated in front of the stage. The broadcast of One Man, Two Guvnors began with a sweeping shot coming over the theatre audience before settling on the skiffle band playing their instruments before the start of the play. Two minutes into the broadcast, as the song finished, it cut to a wide angle shot from the back of the stall as the audience burst into applause. From that point there was a slow zoom over the applauding audience as the curtain rose, the theatre lights went down, and the first scene began. It was an establishing shot for the performance space and the auditorium, making clear the spatial relationship between the performers and theatre audience for those watching at home.

In livecasting the footage of the audience serves to convey the spatial dynamics of the auditorium for the cinema audience. They don't have physical access to the space, so this is important for communicating the experiential aspects through filming conventions. It also 
reinforces the sense of immediacy. There were several points in the performance of One Man, Two Guvnors where the actors engaged directly with the audience. The main character Francis (James Corden) brought on two volunteers to help him move some props in an early scene and later on he asked some audience members for date ideas. Both times the camera focused on the front few rows of the auditorium, going below the level of the stage. Positioning the camera in the stalls, both to establish the space and reinforce the presence of the theatre audience, sends a message to their counterparts in the cinema: these spectators in the theatre are doing the exact same thing as you at the exact same time.

However, with National Theatre at Home, the viewer knows this is not true. The audience's position, their presence and their behaviour all reinforce this. The cinema audience could not be directly involved in the participatory aspects of the performance when it was an NT Live broadcast, but the immediacy created by seeing the audience mitigated this somewhat. In its new iteration the presence of the audience places the livecast firmly in the past, that sense of immediacy gone. The same footage now has the opposite effect on the cinema viewer than it did before. This use of footage of the audience echoes Marriott's words about using pre-recorded footage in live television broadcasts: "To watch such footage at a later date is to be placed in a fundamentally different relation to the event ${ }^{13}$. Images of the audience still filled a contextualising role but rather than reinforcing the liveness of the livecast it reinforced the lack of liveness. Overall, those images helped to create a sense of event where there would otherwise not be one.

\section{The Live Event}

It must be acknowledged that there was an effort on the part of the National Theatre to retain as much of the sense of event as possible when scheduling the National Theatre at Home programme and the paratextual material that accompanied it. From the start of the programme the liveness was built up around the broadcast. The initial streams began at 7pm every Thursday. The play was introduced on social media and there were one hour and thirty-minute calls on Twitter. Sometimes performers and directors would live tweet throughout the performance, creating a sense of immediacy

\footnotetext{
${ }^{13}$ S. Marriott, op. cit., p. 6.
} 
with both performers and spectators. For example, Gillian Anderson took questions on Twitter during A Streetcar Named Desire and the cast of Coriolanus hosted a video reunion on the National's YouTube channel ${ }^{14}$. These paratexts gave the experience a sense of immediacy, situating the broadcast as an artefact of an earlier time in the ontological now of the pandemic. Some of them, such as the twitter question and answer sessions, allowed viewers to interact with parts of the experience.

The National also published tweets that encouraged people to pause the initial Thursday broadcast at 8pm to take part in the nationwide Clap For Carers event where people would applaud frontline workers from their doorsteps and windows every Thursday from 8pm. For example: «We'll be clapping for our carers at $8 \mathrm{pm}$. If you'd like to join us, you can pause the feed and pick up right where you left off $\iota^{15}$. The main performance was no longer live despite being situated in a semi-live context, but processes of immediacy and co-presence were at the forefront of the broadcast with the use of these paratexts. This further complicates the issue of defining the "then" and "now" of the broadcast. With the set start time and the aforementioned pre-recorded content, National Theatre at Home is closer to what Friedman describes as (Re)Presentation: «(Re)presentation incorporates both live and taped segments to give the feeling of happening to events we know have already happened ${ }^{16}$. The live context of the premiere combined with the live paratexts meant that the performance, though filmed prior to the pandemic (sometimes years prior) felt like it was happening in that specific moment.

After the initial "going live" moment, the broadcast was available to watch however many times the spectator wished, at whatever time they wanted. Not only had event cinema moved out of the cinema space, it had ceased to be an event in the same way as NT Live because the method of distribution guided the audience engagement so much. There was no longer an obligation on the part of the audience to be in a certain place, either physical or virtual, at a certain time and so the temporal dynamics between the audience and what they were watching was fractured further. This was the most distinctive differ-

\footnotetext{
${ }^{14} \mathrm{https}: / /$ www.youtube.com/watch?v=lqFws30MIYc\&list=PLgBmjHpqgs7r9K4RfCfCvfm1bYd1FF3w\&index=1

${ }^{15}$ https://twitter.com/ntlive/status/1263500304261304322

${ }^{16} \mathrm{~J}$. Friedman, Attraction to Distraction: Live Television and the Public Sphere, Rutgers University Press, New Brunswick 2002, p. 143.
} 
ence between NT Live and National Theatre at Home. Liveness became a spectatorial choice, something that could be opted in and out of depending on taste and circumstances. The fact that the original recording was filmed with a present audience added yet another layer of temporality that could both increase the feeling of an event for those watching the premiere and serve as temporal context for those watching after that.

Due to the multiplicity of temporalities and the choices available to the audiences at home multiple spectatorial practices occurred throughout National Theatre at Home. Several competing institutional and cultural aims had to be reconciled and the audiences had multiple ways to engage with the broadcasts and the productions. One useful framework through which to examine the spectatorial practices and modes of engagement of National Theatre at Home is de Certeau's ideas on the definition of "space" and "place"17. De Certeau defines place as a location where all components adhere to an order he calls «the law of the proper». Not proper in terms of propriety but proper as in every element having a distinct position that cannot be shared with another element. In contrast the elements of space are fluid and mobile. Space is defined by the spatialities and temporalities within it. In short, de Certeau says «space is practiced place»" ${ }^{18}$. Marriott defines "space" and "place" similarly, calling "space" "the set of relations between relevant objects and individuals» while "place" is "the arena in which these relations are structured»" ${ }^{19}$. In both cases "space" is about behaviors and practices and it transcends the physical.

The viewing practices of NT Live and National Theatre at Home are different because they are creating different "spaces". Livecasts intend to create an experience that is as close as possible to attending a live performance. This wasn't possible during the first lockdown but it was possible to adapt to the circumstances by adding that element of spectatorial choice. There was a distinction between those who chose to interact with the live premiere and go live with the broadcast and those who chose to engage in the aftermath. Those that wanted to could try and replicate an NT Live experience (either as a new viewer experiencing something new or an existing viewer for nostalgia) by engag-

\footnotetext{
${ }^{17}$ For further reading, Pascale Aebisher used de Certeau's ideas on this when writing about the live broadcast of Southbank Shakespeare including NT Live broadcasts.

${ }^{18}$ M. de Certeau, The Practice of Everyday Life, University of California Press, Berkeley 1984, p. 117.

${ }^{19}$ S. Marriott, op. cit. p. 10.
} 
ing in the practices that created a certain kind of live or live like space. The performance wasn't live but the practices were, so liveness became a mode of engagement. Those that watched later could still engage as if live, aided by the paratexts and the visual cues of liveness that allowed remnants of the live experience to come through. It was also possible for a viewer to engage in both practices with the same broadcast. Arguably at a time when people's movements and behaviours were restricted for safety reasons, choice was a highly prized feature of any experience.

\section{A Pandemic Response}

Right from the start of the National Theatre at Home programme a tension existed between the way in which it was and was not live compared to NT Live. But a tension also existed between the liveness of the distribution method and the choices made around that. Before every performance the following message was played:

Theatres around the world are facing a devastating impact from Coronavirus. Theatre and the Arts are a positive for our community in turbulent times.

As you enjoy this performance, please consider a donation to support this great industry. To support the National Theatre please visit nationaltheatre.org.uk

This message, that in some broadcasts reappeared during the interval period, positioned National Theatre at Home firmly in the "now" of March-August 2020, existing as a reaction to COVID-19 and the lockdown. It called to the immediate situation that spectators found themselves in. National Theatre at Home became a fundraising exercise as it was clear that theatres would not be opening any time soon and it was unknown how much help the creative sector would get. The message was a call to action for the audience in the face of a current and ongoing crisis, allowing for a sense of immediacy and interaction as spectators donated money upon seeing the message. It also made a broader statement about the importance of supporting the arts financially. At the time there were frequent stories in the British media about theatres and other arts venues closing permanently. It became crucial that the cultural importance of such venues were communicated to the public. The National frames itself as «a theatre for everyone ${ }^{20}$ so

\footnotetext{
${ }^{20}$ https://www.nationaltheatre.org.uk/about-the-national-theatre/our-national-work
} 
arguably their response was part of their creative remit, and this message made that explicit in the minds of the audience, prompting a feeling of connection to the institution and the performance.

In Live To Your Local Cinema, Martin Barker outlines five dimensions of liveness when he discusses livecasting, which arose both from audience research done via an online survey completed by 644 respondents ${ }^{21}$ and from similar surveys from larger institutions. These dimensions are Immediacy, Buzz, Intimacy, Expanding Oneself, and Being (in) the audience ${ }^{22}$. All these dimensions relate in some way to the experiential aspects of liveness. An entire paper could be written on how National Theatre at Home navigated these dimensions, how scheduling attempted to generate buzz, how intimacy was formed through social media etc. but in this paper I will focus on "Expanding oneself" because it relates to the lasting effects of the experience, beyond the temporal and spatial parameters of the event. It is also the dimension of liveness that was easiest to replicate through the digital distribution method of National Theatre at Home. Barker notes:

This involves knowing that one may or should go away from the performance added to, enlarged, perhaps changed by the experience. Typical phrasings include 'concentrating on the meanings... getting to understand what they are trying to say... picking up information from programmes, etc... hearing things I didn't know before... bonuses and extras. ${ }^{23}$

"Expanding oneself" implies a connection between the text, the personal and something greater. Taking expanding to mean growth, the term suggests that the livecasts' temporal connection to the world in which it is released gives the audience the opportunity to learn something new or achieve some type of growth within themselves. This not always tangible. The terminology Barker picks up on can be suggestive of emotional, social or cultural growth. I would argue that because National Theatre at Home was curated gradually and responsively, in small increments as lockdown progressed, it included productions that would resonate with the zeitgeist, changing audiences, and with the shifts in social and cultural dynamics that the pandemic precipitated.

\footnotetext{
${ }^{21}$ M. Barker, Live To Your Local Cinema: The Remarkable Rise of Livecasting, Palmgrave Macmillan, Houndmills 2012, p. 24.

22 Ivi, pp. 65-66.

23 Ivi, p. 66.
} 
There were multiple and competing factors informing the programming choices behind National Theatre at Home. The series had to entertain, provide comfort or distraction, serve as a fundraising tool for the National while also resonating with audiences. To return to de Certeau's arguments on "space" creation, the practices of engagement create a sense of community in the disparate audiences, facilitating the process of "Expanding oneself".

As mentioned previously, the opening group of plays replicated the variety of the pilot season. However as lockdown and the National Theatre at Home programme both progressed the needs and experience of the audiences changed and the programme began to select plays that featured more political content or that addressed issues and events featured heavily in the media and at the forefront of public consciousness. This House is about a government struggling to stay in power through successive crises; The Madness of King George is about a leader becoming too ill to rule and the struggle of those around him to cope; Coriolanus is about a charismatic leader who crucially misjudges the mood of the people. While it may be a step too far to argue that there are direct or explicit parallels between the content of these plays and the social or political situation at the time of National Theatre At Home, for viewers watching in the UK, certain images and themes definitely resonated in the context of the lockdown and the pandemic.

There were also broadcasts that addressed issues beyond the pandemic. For example, National Theatre at Home screened Les Blancs from 2nd to 9th July. Set in a fictional African country and written by the acclaimed African American playwright Lorraine Hansberry, Les Blancs deals with imperialism, racism, colonialism, and their inherent and resultant violence. Small Island, an adaptation of Andrea Levy's novel of the same name exploring the lived experiences of Jamaican immigrants to the UK, was streamed between the 18th and 25th June to mark Windrush Day 2020. Notably, both productions were announced shortly after the murder of George Floyd by police in the US on 25th May and the subsequent surge in Black Lives Matter and anti-racism protests globally.

Lockdowns and restrictions on travel, mass gatherings, and social distancing made quick responses in the form of performances hard. Les Blancs, This House and the other plays mentioned above, having been created and staged before 2020, were not a direct or explicit response to real world happenings at the time of their rebroadcast. However, the 
programming of those particular performances could be seen as an attempt to formulate a response or at least to draw connections between art and reality though whether or not such a response is effective or goes far enough is outside of the scope of this paper.

\section{Conclusion}

The temporality of National Theatre at Home was complex, almost codified by its most contradictory elements, reflective of the period of flux and uncertainty during which it came into being. It retained all the aesthetics of a live event but only some of the live experience of NT Live or live theatre performances and was simultaneously a nostalgic product and in-tune with contemporaneous events. There was a greater accessibility than there was with NT Live. While this mitigated the absence of a completely live experience encountered in NT Live or a live performance, a consequence of this was the alteration of the audience experience in key ways. It is reflective of the confusion currently being experienced by all. Livecasting in its current form is still so new that it is conceivable that such a seismic upheaval will affect the medium's development, though it may be some time before we fully realise how. While it is difficult, and possibly even unhelpful, to speculate about the longterm future of livecasting as both a medium and an industry, there are some insights to be garnered from an examination of the National theatre's output since the end of lockdown restrictions in the UK.

In December of 2020 the National Theatre announced they were launching a streaming service, also called National Theatre at Home. A new set of practices define a new "place" and a new "space". Spectators choose how to engage in multiple ways now: they can choose from a list of productions - a list that is constantly being updated - they can choose when they watch (providing the recording is still on the site) and because the service is available via phone, tablets and and smart TVs they can even choose where they watch and with whom. There is no simultaneity or immediacy, no premiere where a spectator can engage in communal practices and "space" creation. While viewers could create a sense of event themselves by watching with friends or family or sharing the experience on social media, that sense of live event is no longer a key component of the experience. 
The theatre "spaces" are both physical and digital now as the practices by which these "spaces" are created have grown in number. In September 2021, the National rebroadcast 2017's Follies in cinemas, and broadcast their film version of Romeo and Juliet that was made during lockdown and originally broadcast on Sky Arts. These could only be viewed in the cinema on a set date, at a set time like the original NT Live broadcasts. They weren't available on the streaming service at the same time but for National Theatre productions there are now multiple routes to engagement. Live performances returned to the National's Southbank theatre and finally, in October 2021, the National announced a season of four livecasts in early 2022 that follow a similar formula to the pilot season and first four weeks of the YouTube broadcasts. This includes a piece of new writing, a Shakespeare play, an adaptation of a novel and a musical based on a fairy tale. This re-opening season is a statement about the scope and scale of the National's offerings. It gives an insight and set expectations for new viewers and for returning viewers it establishes consistency and re-affirms expectations in line with the original remit of NT Live.

National Theatre at Home did not mark the end of one era of livecasting in the UK, nor was it an isolated digression from the initial established form of the medium. Instead, it demonstrated that there are many forms and that the key conventions of livecasting, the replication of some kind of live experience -or the remnants of a live experience - can manifest in multiple ways. While it is difficult to guess how livecasting might develop in the future it is clear that a multiplicity of spectatorial choices will remain available to audiences and that liveness will be a part of that in varying and complex ways.

\section{References}

P. Aebischer, Southbank Shakespeare Goes Global: Broadcasting from Shakespeare's Globe and the National Theatre, in P. Aebischer, S. Greenhalgh, L. E. Osborne (eds.) Shakespeare and the "Live" Theatre Broadcast Experience, Bloomsbury, London and New York 2018, pp. 113-132.

M. Abrahams, F. Tuck, Understanding the Impact of Event Cinema, an Evidence Review, Arts Council England, British Film Institute 2015.

S. Atkinson, H. Kennedy, Live Cinema Presents...Cultures, Economies and Aesthetics, in S. Atkinson, H. Kennedy (eds.) Live Cinema: Cultures, Economies and Aesthetics, Bloomsbury Academic, New York 2017, pp 1-14. 
H. Bahkshi, D. Throsby, Digital Complements or Substitutes? A Quasi-Field Experiment from the Royal National Theatre, in «The Journal of Cultural Economy», vol. 1, n. 31, pp. 1-8.

M. Barker, Live to Your Local Cinema: The Remarkable Rise of Livecasting, Palgrave Macmillan, Houndsmills 2012.

D. Dayan, E. Katz. Media Events: The Live Broadcasting of History, Harvard University Press, Cambridge and London 1992.

M. de Certeau, The Practice of Everyday Life, University of California Press, Berkeley 1984.

J. Friedman, Attraction To Distraction: Live Television and the Public Sphere, in J. Friedman (eds.) Reality Squared: Televisual Discourse On The Real, Rutgers University Press, New Brunswick 2002, pp. 136-154.

J. Gray, Show Sold Separately: Promos, Spoilers, and Other Media Paratexts, New York University Press, New York 2010.

N. Hytner, Phèdre pre-show interview with Jeremy Irons, NT Live, 25th June 2009 (accessed at the National Theatre archive).

J. Jacobs, The Intimate Screen: Early British Television Drama, Oxford University Press, Oxford 2000.

B. Karpf Reidy, B. Schutt, D. Abrams, A. Durski, From Live-to-Digital: Understanding the Impact of Digital Developments in Theatre on Audiences, Production and Distribution, Arts Council England, UK Theatre, Society of London Theatre, AEA Consulting 2016.

S. Marriott, Live Television: Time, Space, and the Broadcast Event, Sage, Los Angeles 2007.

\section{Sitography}

Coriolanus Cast Reunion with Tom Hiddleston, Josie Rourke and Deborah Findlay: https://www.youtube.com/watch?v=lqFws30MIYc\&list=PLJgBmjHpqgs7r9K4RfCfCvfm1 bYd1FF3w\&index=1 (accessed 24 November 2021)

Event Cinema Association About Us: https://eventcinemaassociation.org/about-us/ (accessed 1 November 2021)

National Theatre at Home - Frankenstein: https://www.nationaltheatre.org.uk/shows/nt-athome-frankenstein (accessed 2 November 2021)

National Theatre at Home Playlists: https://www.youtube.com/c/NationalTheatre/playlists (accessed 8 November 2021)

National Theatre at Home - Our National Work: https://www.nationaltheatre.org.uk/aboutthe-national-theatre/our-national-work (accessed 9 November 2021) 
National Theatre Clap For Carers Tweet: https://twitter.com/ntlive/status/1263500304261304322 (accessed 17 November 2021)

National Theatre's You Tube Channel: https://www.youtube.com/c/NationalTheatre (accessed 2 November 2021)

\section{Author's Biography}

Sarah Byrne is undertaking her PhD at the University of Reading researching the development of Theatre Livecasting in the UK from 2009 onwards. Her thesis focuses on the structure and aesthetics of livecasts, how they navigate multiple temporalities and engage with liveness, remediation, and intermediality. Sarah has previously presented her work at the Screen Studies Conference, Live Cinema 3, BAFTSS Conference and the 2021 symposium Changing Perspectives on Live Performance: interrogating digital dimensions and new modes of engagement.

Sarah Byrne sta svolgendo un dottorato di ricerca presso l'Università di Reading sullo sviluppo del livecasting teatrale nel Regno Unito dal 2009 in poi. La sua tesi si concentra sulle strutture e le estetiche del livecast, su come esse navigano temporalità multiple che coinvolgono la liveness, la rimediazione e l'intermedialità. Sarah ha presentato il suo lavoro alla Screen Studies Conference, Live Cinema 3, BAFTSS Conference e al simposio "Changing Perspectives on Live Performance: interrogating digital dimensions and new modes of en-gagement" (2021).

Articolo sottoposto a double-blind peer review 